\title{
O OFÍCIO DE TRADUZIR E SUAS IMPLICAÇÕES
}

\author{
Maria Cecilia Pereira*
}

RESUMO: O tema deste artigo é a tradução com enfoque na literária, pois tem sua complexidade ampliada pela ação conotativa e é a que exige, de quem exerce esse ofício artesanal e artístico, um esforço intelectual maior. Na tradução, as palavras e temas estão amalgamados de subjetividade e ambiguidades, que ensejam a abertura de um leque de interpretações tais, que resultam na difícil tarefa de verter para a língua, que não a do autor, o que esse disse e sentiu. O destaque aqui será para a essência literária: a linguagem poética. É preciso considerar na trajetória deste ofício as diferenças culturais e seus valores e manter particularidades de estilo, sem o comprometimento do texto original. Ocorre com frequência mostrar-se a tradução impermeável, isto é, impossibilitar a busca do equivalente na língua para a qual se traduz. Cabe então, ao tradutor, agir com eficiência e bom senso para que não se produzam absurdos tradutórios. O texto reflete também sobre a ética do tradutor e algumas de suas posturas e fatores essenciais, tais como: respeito (com o texto, o autor, o leitor e consigo mesmo), fidedignidade, ampla cultura geral, predisposição à pesquisa e um longo "etecétera”.

PALAVRAS-CHAVE: Platero — Transcriar — Pesquisa

RESUMEN: El tema de este artículo es la traducción con enfoque en la literaria, pues tiene su complejidad ampliada por la acción connotativa y es la que exige, de quien ejerce ese oficio artesanal y artístico, un mayor esfuerzo intelectual. En la traducción, las palabras y temas se amalgaman de subjetividad y ambigüedades, que admiten la apertura de un abanico de interpretaciones tales, que resultan en la dificil tarea de verter para la lengua, que no la del autor, lo que ése dijo y sintió. Aquí se destaca la esencia literaria: el lenguaje poético. Hay que considerar en la trayectoria de ese oficio las diferencias culturales y sus valores y así mantener particularidades de estilo, sin comprometer el texto original. Frecuentemente se pone la traducción impermeable, es decir, imposibilita la búsqueda del equivalente en la lengua para la cual se traduce. Cabe, entonces, al traductor actuar con eficiencia y discernimiento para que no se produzcan absurdos traductorios. El texto reflexiona también acerca de la ética del traductor y algunas de sus posturas y factores esenciales, tales como: respeto (con el texto, el autor, el lector y consigo mismo), fidedignidad, amplia cultura general, predisposición a la investigación y un largo "etecetera".

PALAVRAS CLAVE: Platero-Transcrear-Investigación

\footnotetext{
* Mestre em tradução literária na área de Língua Espanhola e Literaturas Espanhola e Hispano-Americana Instituição: Universidade de São Paulo - USP. E-mail: cecyp98@uol.com.br.
} 


\title{
TRADUZIR E REFLETIR: AÇÕES SIMULTÂNEAS
}

\author{
Mi oficio de cantor (traductor) es el oficio \\ De los que tienen guitarras (palabras) en el alma \\ Yo tengo mi taller en las entrañas (en la mentecorazón) \\ Y mi única herramienta es la garganta (el conocimiento) \\ (Parafraseando "Cantor de oficio", de A. Morelli- argentino)
}

Pensando-se nos pressupostos do exercício tradutório, é comum a reflexão sobre o ofício do tradutor e a complexidade da ação e da arte de traduzir. Pensada como ação devido à dinâmica que envolve a aparentemente simples tarefa de verter palavras, conceitos e significados de um idioma a outro; pensada como arte, porque tal como um poeta parnasiano, o tradutor "aprimora" e "lima" a palavra ou a frase e tal como o ourives, tenta encaixá-la perfeitamente no engaste do texto. Assim se constrói essa "ponte necessária" que trará e levará a voz de outras culturas, permitindo que unidades linguísticas tornem-se compreensíveis nessa Babel.

Arrojo usa a metáfora "oficina de tradução" para explicar, através de todas as acepções dicionarizadas da palavra oficina, o ofício da tradução, como "uma das mais complexas de todas as atividades realizadas pelo homem" (1999, p. 10). É muito conveniente a metáfora, principalmente a que remete à acepção de sentido figurado, "lugar onde se opera transformação notável" (1999, p. 10), pois, numa oficina, palco de criações e de soluções para coisas, muitas vezes "inconsertáveis", pode-se encaixar a labuta que é o traduzir. Trabalha-se exaustivamente em tal oficina, com vistas ao embelezamento e à funcionalidade do que possa servir a outrem e veicular outras transformações. Para Arrojo

\footnotetext{
traduzir é uma atividade extremamente complexa [...] exige do tradutor a capacidade de confrontar áreas específicas de duas línguas e de duas culturas diferentes, e esse confronto é sempre único, já que suas variantes são imprevisíveis. (ARROJO, 1999, p. 78)
}

Ao refletir sobre essa complexidade é necessário ver o lado bom e proveitoso e pensar que o complexo nem sempre é só complicação. Pode-se inferir daí que o complicado significa grande riqueza de detalhes ou aspectos a serem pesquisados. $\mathrm{O}$ que leva tradutores ao desespero resultará, certamente, em grande faina, mas também em acréscimo para elucidar tópicos obscuros ou carregados de valores idiossincráticos, contextos claros apenas para os falantes da língua que se apresenta "intransponível". A tradução é uma atividade linguística por excelência e, como atividade linguística, as formas sintáticas, semânticas e pragmáticas interpenetram-se na interpretação de um texto de partida para um outro, de chegada. Essa complexidade não atinge apenas o campo lexical em sua literalidade, avança pelo emaranhado da tessituras das palavras, e, em caso especial, na abundância conotativa e subjetiva dos textos literários. Se a dificuldade de encontrar correspondência se ameniza na família de línguas românicas, no tronco linguístico não românico, essa passagem traz dificuldades e é corrente o problema. Isso fará surgir certamente imagens de transferência que não parecerão adequadas. Porém, afirma Octavio Paz que

Todo esto debería haber desanimado a los traductores. No ha sido así: por un movimiento contradictorio y complementario, se traduce más y más. La 
razón de esta paradoja es la siguiente: por una parte la traducción suprime las diferencias entre una lengua y otra; por la otra, las revela más plenamente [...] (PAZ, 1990, p. 12)

É preciso reconhecer que no processo tradutório há essencialmente o caráter criativo; traduzir não é somente transferir, trocar palavras de um idioma a outro, é muito mais um ato de transformação, no qual pesa a capacidade de interpretação do tradutor, de sua "leitura" do texto de partida. O ato de ler, com seus níveis sensorial, emocional e racional, inter-relacionados e simultâneos, contém o elemento decodificador que impulsiona, na maioria das vezes, a vontade de querer ir além, de conhecer mais.

Segundo Arrojo, "aprender a traduzir significa necessariamente aprender a "ler" (ARROJO, 1999, p.76). Refere-se a esse "ler" como produção de significados que possam ser "aceitáveis" para a comunidade cultural na qual se insere o leitor desse texto. A constatação de ser a leitura "devoradora" um ponto essencial para o início do processo tradutório é compartilhada com outros praticantes do ofício que pensam ser a tradução uma leitura, e muitas releituras atentas, atentíssimas (grifo meu) do texto. É preciso perceber que o tradutor não faz a mesma leitura dos demais, porque "não lê para si, lê o outro, lê um outro radicalmente outro porque se expressa com outras palavras, com outro estilo, a partir de uma subjetividade outra, estranha, estrangeira" (BERLINER, 2003, p. 75).

Arrojo cita Haroldo de Campos ao comentar sua tradução de um poema de Maiakóvski: "Foi, para nós, a melhor leitura que poderíamos jamais ter feito do poema[...]" (ARROJO, 1993, p. 52). Gregory Rabassa afirma o fato de a leitura intensa propiciar a tradução. "Sempre achei que a tradução é, em essência, a leitura mais próxima que se pode fazer de um texto" (ibid., p. 53). Acionaria, então, essa leitura, o mecanismo de interpretação e o questionamento de que traduzir é interpretar?

Theodor escreve que "um dos propósitos" que norteia seu livro é "demonstrar quão importante é a interpretação correta do texto original pelo tradutor, para que o mesmo possa ser devidamente compreendido pelos leitores" (THEODOR, 1976, p. 54). Quando se reflete sobre a questão suscitada, surgem outras: o que seria interpretação "correta" e até onde deveria ir essa interpretação para ser o texto "devidamente compreendido"? Não parece clara essa afirmação, porque, principalmente no que se refere ao poético, em fazer-se concessões ao leitor, corre-se o risco de minimizar linguagens ou estilos e reduzir enunciados ou até banalizar contextos. Arriscar-se a "facilitar" a leitura ao leitor em detrimento do texto? Para essa forma de pensar que consiste em "manter o sentido" como fator primordial, Arrojo diz que "sobra um problema insolúvel", pois, se é o tradutor um transformador da linguagem, não poderá manter intacto um tex to manipulado e intermediado (ARROJO, 1993, p. 55).

Declara Mounin a respeito dessa impossibilidade, que para a linguística contemporânea a atividade de tradução é um problema teórico, porque diante da estrutura dos léxicos, das morfologias e das sintaxes, ela seria impossível, porém, segundo ele "os tradutores existem, eles produzem, recorremos com proveito às suas produções” (MOUNIN, 1975, p. 19). Se possível, então, na prática, pois há milênios acontece a atividade tradutória, o ponto de equilíbrio entre a teoria e a prática parece situar-se num ponto qualquer entre o bom senso dos que traduzem em relação à permeabilidade ou não dos textos-fonte e à apreensão dos mesmos pela comunidade cultural que os recebe.

Atualmente, cada vez mais exercido, o ofício de traduzir é lugar de estudo, de pesquisa e de reflexões quanto à dicotomia possibilidade/impossibilidade da realização 
tradutória, não somente por filósofos e linguistas, mas também pelos que traduzem; interessantes deduções e observâncias sobre o próprio processo de trabalho em exemplos felizes de transposição.

Que precisa o leitor-tradutor para transpor a linha de chegada com sucesso? Certamente não haverá fórmulas ou receitas infalíveis, nem atalhos planos. Possuir ampla cultura geral e grande conhecimento do idioma para o qual traduz (frequentemente é seu próprio idioma) é bagagem certa e necessária.

\begin{abstract}
Assim, quanto mais bem informado for o leitor, quanto melhor conhecer sua comunidade cultural, quanto melhor conhecer a obra do poeta que pretende ler, quanto maior for a sua prática como leitor de poemas, melhor e mais bem-sucedida será sua leitura. (ARROJO, 1999, p. 77)
\end{abstract}

E isso vale não só para o leitor-tradutor de obras poéticas, obviamente, mas para toda obra literária e também para as não literárias. Segundo Alfarano "a atividade tradutória exige disciplina na pesquisa [...] pressupõe atualização constante [...] a formação como um todo é fundamental" (ALFARANO, 1990, p. 36-37). Essa "bagagem" da qual deve munir-se o tradutor é pactuada pela maioria, tanto de teóricos como de praticantes do ofício e, além desses componentes que servem de alicerce, afirma Barbosa que o tradutor precisa ter "desconfiômetro"; o pressuposto de que este profissional tem de saber "tudo" não é verdadeiro, porque é algo impossível. O "desconfiômetro seria 'aquela vozinha interior' que diz a ele que deve pesquisar e desconfiar sempre" (BARBOSA, 1990, p. 58).

García Yebra afirma que "ser traductor significa ejercer el noble oficio de comunicar entre sí a hombres separados por barreras lingüísticas total o parcialmente infranqueables para ellos" (GARCÍA YEBRA, 1989, p. 9). Essa definição para o tradutor resume singelamente o papel deste como elo entre culturas. Sem sua ajuda não seria possível transpor a barreira linguística para conhecer outro âmbito cultural, outras vias de pensamento que formarão outras leituras de mundo, pois é certo que o confinamento empobrece a língua, como toda autarquia, e não possibilita o elemento comparativo. Ao exercer esse ofício, o tradutor se adentra em uma produção que não é sua, mas da qual se apropria para empreender e buscar em um território de palavras de outro idioma as que melhor abram os significados para o idioma vertido. É um portavoz de vozes estranhas, que as torna perceptíveis, sem travas de tempo ou espaço. Segundo Rónai, a tradução é

\footnotetext{
o único exercício realmente eficaz para nos fazer penetrar na intimidade de um grande espírito. Ela nos obriga a esquadrinhar atentamente o sentido de cada frase, a investigar por miúdo a função de cada palavra, em suma a reconstituir a paisagem mental do nosso autor e a descobrir-lhe as intenções mais veladas. (RÓNAI, 1981, p.31)
}

No caso do exercício tradutório poético, por seus pluriaspectos, vigora a interpretação como fator indispensável para "ler adequadamente o poema", pois isso, segundo Arrojo, "implica conhecer a concepção de poesia que o criou e saber aplicar as convenções estabelecidas para sua leitura" (ARROJO, 1999, p. 76-77). E declara que não se descarta "nenhum fragmento que possa ser empregado na construção de uma interpretação" (id., 1999, p. 76-77). Tampouco, diz ainda, devem-se ignorar elementos que aparentemente nada significam e que o poema ao ser lido transforma-se em uma 
"máquina de significação". (ibid., p. 52). Tais elementos podem fazer parte do semântico, lexical ou gramatical, ou então, do ritmo do verso e ainda do fônico.

Tomem-se como exemplo os três versos finais de Tecendo a manhã, de João Cabral de Melo Neto. Na tradução espanhola de Pablo del Barco ${ }^{1}$ se apresentam assim:

(a manhã) que plana livre de armação

A manhã, toldo de um tecido tão aéreo

que tecido, se eleva por si: luz balão. (la mañana) que planea libre de armazón La mañana, toldo de un tejido tan aereo que, tejido, se eleva por sí: luz globo.

$\mathrm{Na}$ citada tradução, há a perda da rima armaçÃO/balÃO que, tão sonora, intensifica a imagem dessa luz-balão, parece ser possível visualizar a manhã subindo.

$\mathrm{Na} l u z$ globo da tradução espanhola, o fonema oclusivo incisivamente impossibilita a sonorização, tão precisa nesses versos finais. A palavra é seca, fechada, escura; mata a claridade da luz da manhã. Perdeu-se a poeticidade e não atingiu a significância, embora tenha sido preservado o sentido da palavra do texto-fonte.

Causa estranheza em português do Brasil, "globo" e "balão" como assemelhados, ou seja, pensamos essas palavras como objetos completamente diferenciados. Não seria comum visualizar em nosso idioma um globo subindo pelos ares. Porém, para falantes do espanhol, embora sem musicalidade, o verso soaria compreensível.

Numa transposição em moldes criativos, a essência da sonoridade e da imagística seria mantida, levando-se em conta esses detalhes muito mais que o próprio significado literal de palavra a palavra. John Milton, citando Paul Valéry, escreve: "Um poema e a tradução de um poema deveriam criar a conjunção indissolúvel de $o$ som e $O$ sentido" (MILTON, 1998, p. 144).

Creio, como José Paulo Paes ${ }^{2}$, que não se deve criticar sem apresentar uma alternativa, portanto, minha solução seria a que apresento: talvez venha a ser uma escolha feliz.

\section{(la mañana) que planea libre de cadenas La mañana, toldo de un tejido tan aereo que tejido, se eleva por sí: luz-alas.}

A opção pela palavra cadenas parece "vestir" bem o vocábulo a ser vertido, pois está a manhã sem amarras e em espanhol é uma das acepções possíveis deste termo. Mantêm-se as aliterações L/ T/ J, e num sistema de compensação, o $\mathrm{N}$ em cadeNas, se junta às aliterações já existentes em mañaNa, em plaNea, em $u N a$ e indiretamente em taN Aereo, na junção da consoante e vogal. O vocábulo alas mantém a rima cadenaS / alaS e as sibilantes que se ouvem na junção LuZ Alas e no "s" final permitem preservar a idéia da manhã, não subindo como um balão, porém subindo lentamente em vôo ciciante. Parece-me possível assim, preservar a musicalidade e a significância.

Em campo semântico, os exemplos são muitos, em muitas traduções. Em $E l$ pozo, do poema em prosa juanramoniano ${ }^{3}$ : Por el pozo se escapa el alma a lo hondo.

Na tradução: "Do poço escapa a alma das profundezas" (DAMASCENO, 1997, p. 88) há uma inversão de valores no que faz referência à ação que envolve a alma, pois

\footnotetext{
${ }^{1}$ Poeta, tradutor e professor-doutor em Literatura Espanhola na Universidade de Sevilha-Espanha.

2 Tradutor e poeta.

${ }^{3}$ Refere-se a Juan Ramón Jiménez na prosa poética espanhola , Platero y Yo, cap.LII, El pozo, p.151.
} 
escapa ela em direção ao profundo, ou seja, imerge à profundidade da qual o poço é a metáfora.

$\mathrm{Na}$ tradução, além da perda fônica de $\mathrm{pOzO} / \mathrm{hOndO}$, já palavras fechadas, sem luz (como o interior do poço), a palavra "profundezas", pela extensão, faz perder a musicalidade; há na interpretação uma operação inversa, pois sai a alma como se estivesse liberta da profundidade. O eu-lírico se propõe reclusão e quietude de pensamento, uma imersão e não emersão. A "informação estética" não foi preservada.

Aqui se chega, no entanto, a uma questão crucial: pode esse "erro" de significância ser fruto da interpretação do tradutor, portanto, prefiro chamar de diversidade interpretativa o que parece ser um equívoco ou uma solução inadequada. Em um sistema de compensação, pela referida observação feita à tradução citada, ofereço minha transcriação para este verso:

\section{Pelo poço some a alma ao profundo}

Nesta solução tradutória foi possível manter a aliteração em "p" e em "o"; PelO/ $\mathrm{POçO/} \mathrm{PrOfundO/} \mathrm{sOme,} \mathrm{que} \mathrm{colaboram} \mathrm{com} \mathrm{a} \mathrm{imagem} \mathrm{fechada} \mathrm{do} \mathrm{interior} \mathrm{do} \mathrm{poço.}$ No termo "sumir" acontece a introspecção da ação ocorrida com a alma, as águas parecem tragá-la. A palavra hondo, em espanhol, é mais que "fundo", tem o peso do adjetivo "profundo". Este, na locução "ao profundo", assume valor de advérbio e reforça nesta possibilidade tradutória a imagem da alma sendo levada ao interior, às profundezas.

"Pelo poço" significa "através de", enquanto que "do poço", da tradução cotejada, significa "vir de", "vir dele", ou seja, a ação de dentro para fora, contrária, portanto, da informação introspectiva do texto-fonte.

Ocorre também, frequentemente, um grande promovedor de cincadas: o "cortar caminho", fruto de desatenção e descuido na hora de traduzir. Declara José Paulo Paes:

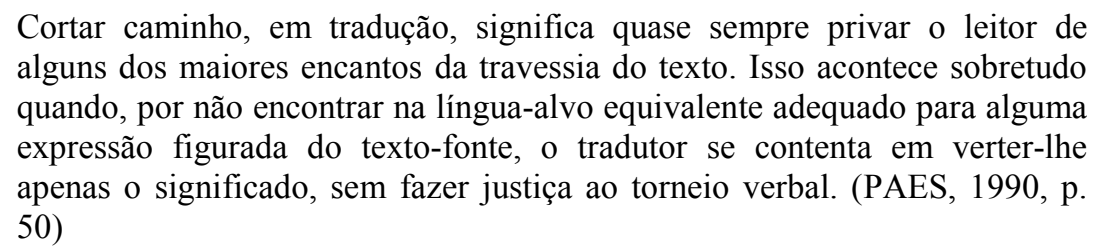

No transcorrer da lida se acrescenta a sensação frustrante das limitações de algumas soluções tradutórias, da resistência que, muitas vezes, a língua de destino apresenta à atividade, e que a tradução na qual se labora, por vezes estará distante de uma recriação satisfatória do texto-fonte ${ }^{4}$.

Casos, por exemplo, de regionalismos ou neologismos e de tantos trejeitos léxicos dos quais se servem muitos autores como traço estilístico ou enfático. É, muitas vezes, ofício sisífico, de esforços vãos, de soluções mal aparadas, de conclusões inconclusas. Assume, por vezes, caráter messiânico, como o empreendido por $\mathrm{Nida}^{5} \mathrm{e}$ sua equipe na tradução da Bíblia para levá-la aos confins do planeta em inumeráveis idiomas.

\footnotetext{
${ }^{4}$ Houve por bem optar pelo uso dos termos texto-fonte e língua-meta para designar o momento de saída e de chegada de um texto. Embora muitas sejam usadas, estas parecem-me as mais adequadas. Fonte: como manancial, de onde nasce e de onde se buscam os significados, e meta, porque buscar equivalentes nessa fonte e levá-los a outra fonte é meta séria e dificultosa, um objetivo a concretizar.

${ }^{5}$ Eugene Nida, lingüista norte-americano, especialista em traduções da Bíblia.
} 
Segundo John Milton, para Nida, a forma tem menos importância que a mensagem, pois tudo tem de ficar muito claro na língua-meta, e que para Nida o fator essencial é o público, os receptores da tradução (MILTON, 1998, p.169-170).

Paulo Rónai também alude à dificuldade da equipe de Nida para traduzir termos holofrásticos para línguas primitivas e atingir o objetivo buscado: a captação da mensagem pelos falantes das línguas em questão (RÓNAI, 1981, p.45-46). São fatos mais ou menos isolados, mas mostram que o traduzir é multifacetado, que possui muitas direções e objetivos que servem a diversos públicos-alvo e a diferenciados receptores.

García Yebra relata que algumas dessas línguas são ágrafas, e que, às vezes, traduzir o texto bíblico implica criação de um novo alfabeto. Termina sendo, então, a primeira obra escrita e uma possível origem de literatura (GARCÍA YEBRA, 1989, p. 302). Trabalho digno de nota, certamente, mas Nida é criticado, por vezes, com a acusação de ter destruído a língua de partida, o hebraico, e por sua cegueira "a especificidade literária de um texto" (MILTON, 1998, p.171).

Outras vezes é trabalho estafante, nada prazeroso. O personagem-narrador do romance espanhol Corazón tan blanco, de Javier Marías, relata suas peripécias como tradutor-intérprete dentro de organismos internacionais. Relatando e refletindo sobre seu trabalho, leva-nos a conhecer o dia a dia desse profissional, que tem uma carga maior de responsabilidade sobre sua tradução, pois é produzida no momento e não permite retificações. Deve estar totalmente concentrado, pois não sabe que termos virão, se é discurso formal ou coloquial, em suma, não há tempo para pensar na busca de uma palavra precisa, só há tempo para repetir numa língua o que ouve em outra.

Ele desabafa e nos põe a par de como funciona essa forma de traduzir.

Lo cierto es que en esos organismos lo único que en verdad funciona son las traducciones, es más, hay en ellos una verdadera fiebre translaticia, algo enfermizo, algo malsano, pues cualquier palabra que se pronuncia en ellos (en sesión o asamblea) y cualquier papelajo que les es remitido, trate de lo que trate y esté en principio destinado a quien lo esté o con el objetivo que sea (incluso si es secreto), es inmediatamente traducido a varias lenguas por si acaso. (MARÍAS, 1992, p. 59)

Talvez seja a maneira mais difícil de exercer o ofício de traduzir. No momento em que faz a tradução deve o profissional converter-se em máquina pensante e esquecer tudo o mais relacionado a sua pessoa. Para que leve a cabo a tarefa, ele e seus sentimentos não existem. Se é possível ao tradutor mecanizar-se, seria, então, o tradutor-intérprete o estereótipo dessa ação. Relata-nos o personagem que:

Los traductores e intérpretes traducimos e interpretamos continuamente, sin discriminación ni apenas descanso durante nuestros periodos laborales, las más de las veces sin que nadie sepa muy bien para qué se traduce ni para quién se interpreta [...] (ibid., p. 59)

Novas teorias apontam que a correspondência biunívoca exata entre a tradução e o texto-fonte (o chamado original) é visão tradicionalista, de aceitabilidade bastante restrita em estudos tradutológicos contemporâneos. A imagem da transferência e substituição muito serviu para ilustrar o processo tradutório e nesse conceito, a tradução se resolveria em simples transposição. Estudos e práticas recentes demonstram que teorias como essa resultam em trabalhos imperfeitos e incoerentes. Mário Laranjeira, um desses teórico-praticantes, afirma que "se aceitarmos, como é ponto pacífico em 
tradutologia a simples equivalência, as barreiras podem ser transpostas", porém, em um momento antes em suas reflexões, diz que "se nos contentarmos com a simples equivalência, entretanto, numerosos fatores vão condicionar um grau maior ou menor de tradutibilidade" (LARANJEIRA, 1993, p. 18-19). A tradução sentido-por-sentido, palavra-por-palavra, cria possibilidades de não permeabilidade das palavras e de distanciamento de significados da língua-fonte para a língua-meta, pois como postura rígida deixa espaços vazios de aproximação ${ }^{66}$.

Paulo Rónai, com muito acerto, diz que a palavra não é pensada isoladamente, que ela "existe apenas dentro da frase, e o seu sentido depende dos demais elementos que entram na composição desta" (RÓNAI, 1981 p.34). E afirma que vocábulos podem ser definidos igualmente, porém dentro de seus enunciados terão conotações diferentes. As palavras não possuem sentido isolado, os enunciados é que irão determinar seu sentido dentro da frase ou do contexto. Dependem de outros elementos para completar seu significado, assim, palavras sinônimas podem assumir conotações diversas, sejam em línguas que se confrontam ou na mesma língua. $\mathrm{O}$ valor polissêmico representa armadilhas à vista na ação de traduzir e não apenas em termos cognatos (id.,1981, p.34).

Tão clara é esta verdade, que pensadores e tradutores contemporâneos parecem concordar - a maioria deles — que não é viável traduzir da forma dita "literal", principalmente em casos de tradução literária. Sabem eles das "armadilhas" e têm noção da perda ocasionada por um texto insosso ou ilógico. Rónai salienta que "um punhado de erros de interpretação não inutiliza de todo uma tradução [...] mas um vernáculo desajeitado, emperrado ou pedante, pesadão ou incorreto dificulta a leitura e pode chegar a interrompê-la de vez" (ibid., p.27). Susana Cella, refletindo acerca da ação de traducir, afirma:

\begin{abstract}
la traducción implica mucho más que una lógica de equivalencias, implica también una lógica transformativa que permite incluirla en un conjunto mayor de operaciones traslativas que suponen la interpretación [...] la palabra justa no sólo se refiere a exactitud, se refiere también a justicia, doble justicia porque es necesario hacer justicia, ser justos - en sentido literal y en todos los sentidos posibles - con el traducido y su lengua [...] (CELLA, 2001, p.14-15)
\end{abstract}

O ofício de traduzir, por ser uma atividade reflexiva e seletiva e, portanto, não mecânica, busca mostrar, na tradução literária, efeitos estéticos, despertar emoções nesse outro texto que se tece. A ideia do tecer parece ainda mais perfeita para o processo tradutório, pois o tradutor é o tecelão por excelência. Os fios que chegam a suas mãos exibem cores e tonalidades por vezes nunca vistas, a textura desses fios tem diâmetros que não são os habituais e sua tarefa é fazer a urdidura de uma nova tapeçaria imitando uma anterior, já tecida. Iniciando o labor de reproduzir o mais parecido possível o tecido da outra tapeçaria, constata que às vezes deslizam os fios por entre seus dedos que se movem rápidos, satisfeitos porque flui a urdidura; porém outras vezes, se recusam a adaptar-se ao tear e a parte tecida fica ora irregular, ora ajustada com ressalvas, ora unida perfeitamente à peça, e o tecelão observando, ora aflito, ora preocupado, ora embevecido com o tecer que sai de suas mãos, comandado pela mente

\footnotetext{
${ }^{6}$ Assim como José Paulo Paes, creio ser o conceito de "aproximação" mais fecundo que "equivalência", porque é menos ambicioso e mais abrangente, principalmente em tradução poética (PAES, 1990. In: Notas, p.123).
} 
e pela sensibilidade. Se trabalha exigindo de si o máximo de perfeição, desfruta o tecelão o prazer da tarefa cumprida. Se segue descompromissado, incauto, tecendo fios sem preocupação com a precisão, encontrará certamente leitores cautos, depreciando a trama de seu tecido, dedo em riste.

\section{REFERÊNCIAS}

ALFARANO, R.H.E. Conversas com tradutores - Balanços e perspectivas da tradução. São Paulo: Parábola Editorial, 2003.

ARROJO, R. Tradução, Desconstrução e Psicanálise. São Paulo: Imago, 1993. . Oficina de tradução. São Paulo: Ática, 1999.

BARBOSA, H.G. Conversas com tradutores - Balanços e perspectivas da tradução. São Paulo: Parábola Editorial, 2003.

BERLINER, C. Conversas com tradutores - Balanços e perspectivas da tradução. São Paulo: Parábola Editorial, 2003.

CELLA, S. "Notas acerca de la traducción". Lenguas Vivas - problemas de la traducción. Buenos Aires: Instituto de Enseñanza Superior “Juan Ramón Fernández, $\mathrm{n}^{\mathrm{o}} 1$, diciembre 2000-marzo 2001.

DAMASCENO, A. Platero e Eu. São Paulo: Globo, 1997.

GARCÍA YEBRA, V. En torno a la traducción. Madrid: Gredos, 1989.

JIMÉNEZ, J.R. Platero y Yo. Edición de Michael P. Predmore. Madrid: Cátedra, 2002.

LARANJEIRA, M. Poética da Tradução. São Paulo: Edusp/ Fapesp, 1993.

MARÍAS, J. Corazón tan blanco. Barcelona: Anagrama, 1992.

MILTON, J.Tradução teoria e prática. São Paulo: Martins Fontes, 1998.

MOUNIN, G. Os problemas teóricos da tradução. Trad. de Heloysa de Lima Dantas.

São Paulo: Cultrix, 1975.

PAES. J.P. Tradução: a ponte necessária. Aspectos e problemas da arte de traduzir. São Paulo: Ática, 1990.

PAZ, O. Traducción: literatura y literalidad. Barcelona: Tusquets, 1990.

RÓNAI, P. A tradução vivida. Rio de Janeiro: Nova Fronteira, Col. Logos, 1981.

THEODOR, E. Tradução oficio e arte. São Paulo: Cultrix / Editora da Universidade de São Paulo, 1976. 